\title{
Comparative Analysis of Teacher Education in Kenya, Somalia, and Finland-A Review
}

\author{
${ }^{1}$ Dr Reuben Nguyo Wachiuri, ${ }^{2}$ Jedidah Kimathi, \\ ${ }^{3}$ Badari Shisha Lyngdoh Nonglait, \\ ${ }^{1}$ PhD Lecturer Catholic University of East Africa, Department of Curriculum Department, P.O. Box 4518- \\ 00100 Nairobi \\ ${ }^{2}$ North Eastern Hills University, Meghalaya India \\ ${ }^{3}$ Sngap Syiem College, Meghalaya India:
}

\begin{abstract}
It is no secret that countries which have made adequate and appropriate investments in education are more developed than those which have not. Usually, the quality of education in a country is a critical measure of the quality of its citizens. According to the American Commission on Teacher Education, the quality of teachers in a country largely determines the quality of its education system. This is to say that teachers play a crucial role in the achievement of the national education goals of any country. The teacher is the most important element in any education system because it is the teacher who is mainly responsible for the planning, implementation, and evaluation of educational activities. The teacher is the "soldier" on the ground and is the one who is in direct contact with the intended recipients of the educational services. The availability of competent, qualified, and motivated teachers directly affects the future development of any country Therefore, it is imperative for any country to make appropriate investments in teacher education. Teacher education is defined as "a program for education, research and training of persons to teach from pre-primary to higher education level" (National Council for Teacher Education, 1998). Based on this definition, teacher education entails the holistic development of the teacher in terms of knowledge, pedagogical skills, and professional skills. The student teacher is molded into a well-rounded person who is ready to take on the complex challenges of the teaching profession. The above definition is an inclusive statement in its attempt in capturing the aspects of teacher education. This paper is an exploration into teacher education and its related issues of certification, employment, and professional development in Kenya, Finland, and Somalia. It will then proceed to entry requirements into teacher education programs, program levels, and teaching practice. It will then follow with issues of certification, induction, management of teacher education, and employment contracts in each of the three countries. The paper will conclude with a close examination of the status of the teaching profession in each of Kenya, Finland, and Somalia and also the lessons that can be drawn from each country.
\end{abstract}

\section{Introduction}

The importance of teachers can never be overemphasized. Teachers play an active role in shaping the future of those whom they teach. Therefore, it is imperative for countries to invest in and closely monitor teacher education programs. Teachers need the self-confidence to carry out their duties in demanding unique situations and need to implement their expertise in such a way that their customers, stakeholders and colleagues trust them (Isopahkala- Brunet, 2004). This can be achieved through a systematic, rigorous, modern, and researched-based teacher education program. Loughran (2006) defines teacher education as the pre-service and in-service teacher preparation where students of teaching seek to develop knowledge and skills of teaching and to learn how to competently apply these in practice.

\section{Entry Requirements into Teacher Education in Kenya, Finland and Somalia}

Just like any other higher education program, applicants for teacher education must fulfil certain requirements and standards in each country. As we will come to know, in some countries teacher education is seen as one of the most important fields of study where as in others it may not hold so much prestige and value. In Kenya, there are currently five teacher education programs namely, early childhood development and Education (ECDE), secondary teacher education, technical teacher education, special needs education teacher education, and primary teacher education. Student intake into teacher education is determined by the government through the ministry of education (Katitia, 2015). The entry requirement for Primary Teacher Education (PTE) is a minimum grade of C (plain) in the Kenya Certificate of Secondary Education (KCSE). For secondary teacher education the applicant must have achieved a grade of $\mathrm{C}+$ in the Kenya Certificate of Secondary Education (KCSE). In Finland, the teaching profession is highly prestigious and only a small 
segment of applicants are admitted into teacher education programs. Besides the matriculation exams taken at the end of the upper secondary education, entrance exams are administered to assess areas such as aptitude, studying skills, and interpersonal skills (Finnish Ministry of Education and Culture, 2014). It is important to note that each university decides on student admission and admission criteria independently. Only the brightest of applicants are admitted into teacher education programs in Finland. For example, in 2013 there were 12, 493 applicants who sat for the entrance exam for Finnish language class teacher education program and only 886 were selected. This shows how competitive the teaching profession is in Finland.

In Somalia, there are no clear-cut requirements or criteria for entry into teacher education programs. As a matter of fact, the entire education system in the country is hindered by the scarcity of trained teachers (Cassanelli and Sheikh Abdikadir, 2007). Because of the lack of a uniform and unified education system, there are no distinct standards in teacher education in Somalia. However, there is renewed hope in the establishment of teacher training institutions at Amoud University and Mogadishu University. These two universities have taken steps in preparing qualified and trained teachers with formally recognized certification from all administrative regions in Somalia.

\section{Teacher Education Program Levels and Teaching Practice}

In Kenya, there are currently five teacher education program levels namely, early childhood development and Education (ECDE), secondary teacher education, technical teacher education, special needs education teacher education, and primary teacher education.

Primary teacher trainees undergo one term of teaching practice in Kenya, which is three months of teaching under supervision. Primary teacher education is conducted for a period of two years and teaching practice is usually done in the second year. For secondary teacher education students at universities, teaching practice is also for one term which is three months. This is usually done in the third year of study.

Teacher education in Finland is divided into two levels: basic education teachers and general upper secondary education. Teachers in the first six years of basic education are usually generalists, class teachers, whereas those in the last three years and at upper secondary level are subject specialists, subject teachers (Finnish Ministry of Education and Culture, 2014). Class teachers are required to have a master's degree while subject teachers are required to have a master's degree in the subject they teach as well as pedagogical studies (Education in Finland Series, 2012)

Teaching practice makes up about 25 percent of the time spent on teacher preparation in Finland (Sahlberg, 2011). Unlike the Kenyan system, teaching practice continues in Finland and increases in complexity. Sahlberg (2011) states that "over the five-year program, candidates advance from basic teaching practice, to advanced practice, and then to final practice". This shows the amount of importance placed on teaching practice in Finland.

In Somalia, teacher education programs are of two levels: primary and secondary education. Primary teacher education is usually undertaken in two years at the end of which diplomas are conferred upon the graduates. Secondary teacher education can be done in two years at the end of which a diploma is earned and it is also done in four years earning the graduate a degree in education. Teaching practice is not systematic and can vary from institution to institution. For example, at Amoud University teaching practice is usually for month at the last semester. University of Hargeisa and Mogadishu University may have different periods for teaching practice. The data regarding teaching practice in Somalia is scant.

\section{Certification, Induction and Employment Contracts of Teachers}

In Kenya, teacher trainees are certified by the institution in which they have undertaken their training. For example, at primary teacher training colleges students are given once they have done their exams and passed. It is also the same at the university level. There is no external body tasked with the certification of teachers in Kenya. Once teachers obtain their certificates, degrees and diplomas, they can either be employed by the Teachers Service Commission or by private schools.

Recently, there has been a great debate about performance contracts for teachers although the idea has faced stiff opposition from teachers unions. It is important to mention that the Teachers Service Commission (TSC) employs teachers on a permanent and pensionable basis. Similarly in Finland, universities and polytechnics in which students undertook their teacher training are responsible for certifying the students. The award of degrees is tantamount to certification. Finland does not have a body similar to that of Teachers Service Commission (TSC) in Kenya. The school staff and principal together with the local school board typically make hiring decisions (Sahlberg, 2011). Almost all of the teachers in Finland are members of the Trade Union of Education. There are two types of teacher employment in Finland: fixed term and open-ended. Fixed term employment is usually for just one year. The reason for fixed term contracts is only to cover for teachers on maternity or sick leave. Open-ended employment contracts are the most popular in Finland. This means that a teacher is employed on a permanent basis. There are no performance contracts for teachers in Finland because 
the strong preparation of teachers is a major factor in their employment. Teachers are rarely terminated from their jobs in Finland.

In Somalia, teachers are certified by the universities from which they have graduated. Ministries of educations in the three administrative regions of Somalia recognize and validate the certificates given by most universities. Because of the acute shortage of trained teachers, graduates from teacher education programs usually find work easily. There is no centralized management of education in Somalia and so teachers are hired by individual schools. Also, there are no trade unions for teachers in Somalia. As one can imagine, these teachers are not hired on permanent basis.

\section{Conclusion}

Kenya has made considerable gains in teacher education since its independence. From an education system based on churning graduates with employable skills to one that is learner-centered and technology-based. Kenya's teachers are faced with the immense challenge of adopting and adapting their skills to the changing needs of the learners. Even so, a number of challenges exist in the teacher education sector ranging from inadequate facilities and facilities to lack of pedagogical content knowledge. Teacher employability is also an emerging issue that needs careful consideration.

Many lessons can be drawn from the teacher education program model of Finland. Teaching is a highly desirable occupation in Finland. Finnish teachers undergo a rigorous program of teacher education and are not certified teachers until they gain their master's degrees. Only the top students are recruited into teacher education program. The first lesson that can be drawn from the Finnish teacher education program is the appropriate and adequate investments made in the sector. Although Finland is a well-developed country with the means to finance an elaborate education program, the emphasis is on the quality of the people pursuing a career in teaching. Finland makes sure only the best are admitted into teacher education programs, whereas Kenya and Somalia admit the least qualified and motivated to be teachers. This has to change if the teaching profession is to become desirable and prestigious enough for people to pursue. Those who are admitted into teacher education programs must be intrinsically motivated to become teachers. This can be achieved through the implementation of continues professional development for teachers. That is quality in-service training. Also, entry requirements for teacher education programs must be raised so as to attract those who have the required academic skills to become proficient teachers. Another avenue of strengthening the teaching profession is increasing the salaries of teachers and introduction of performance contracts.

[1] "Education in Finland" series published by Ministry of Education and Culture, Printed in: Kopijyvä, Espoo, 2012

[2] Formal Private Education Network in Somalia (FPENS). Annual Report 2003. Mogadishu,

[3] Somalia, 2004.

[4] Isopahkala-Brunet, U. (2005).Joy and struggle for renewal: A Narrative inquiry into expertise in job Transitions: University of Helsinki, Faculty of Behavioral sciences, Department of Education, Research Report 2005.

[5] Kafu Patrick A. (2011). Teacher Education in Kenya: Emerging Issues, International Journal of Curriculum and Instruction 1(1) 43 - 52, http://www.muk.ac.ke/ijci/,

[6] Katitia, David Melita Ole. (2015).Teacher Education Preparation program for the $21^{\text {st }}$ Century. Which way forward for Kenya? Journal of Education and Practice, 6(24) www.iiste.org

[7] Learning about Teaching. New York: Routledge.

[8] Lee Cassanelli and Farah Sheikh Abdikadir," Somalia: Education in Transition” Bildhaan Volume 7

[9] Loughran, J. (2006).Developing pedagogy of teacher Education; Understanding Teaching and

[10] National Council for Teacher Education (NCTE) (1998) NCTE Document New Delhi, Published by Member Secretary, NCTE

[11] Teacher Education in Finland (2014). Ministry of Education and Culture

[12] Sahlberg, Pasi (2011). Lessons From Finland. The American Educator 